\title{
Evaluation of role of laparoscopy in determining etiology of infertility
}

\author{
Hema K. R.*, Lalitha H. S.
}

Department of Obstetrics and Gynecology, Sree Sidhartha Medical College, Tumkur, Karnataka, India

Received: 11 October 2017

Received: 09 November 2017

Accepted: 04 November 2017

\section{*Correspondence:}

Dr. Hema K. R.,

E-mail: drhema78@gmail.com

Copyright: () the author(s), publisher and licensee Medip Academy. This is an open-access article distributed under the terms of the Creative Commons Attribution Non-Commercial License, which permits unrestricted non-commercial use, distribution, and reproduction in any medium, provided the original work is properly cited.

\begin{abstract}
Background: Although population explosion is a major problem in India, infertility appears to be a problem in 5$15 \%$ of Indian population. All these patients require evaluation. Laparoscopy plays a valuable role in the diagnosis of infertility. After thorough clinical examination and specific investigations, diagnostic laparoscopy is performed to detect patency of tubes, morphological defects in uterus, ovaries and tuboperitoineal factors. This study was conducted to assess the role of diagnostic laparoscopy in the investigation of female infertility and to evaluate the various causes of infertility like endometriosis, PCOD tubal and peritoneal factors, uterine anomalies, tuberculosis etc. by using diagnostic laparoscopy.

Methods: Study was carried out in 60 infertile patients attending outpatient department of hospitals attached to Sri Siddhartha Medical College Hospital, Tumkur. Both primary and secondary infertility patients who were anxious to conceive and undergo diagnostic laparoscopy were evaluated. Those who were not willing and who were contraindicated for the procedure were excluded.

Results: Diagnostic laparoscopy was performed in $72 \%$ of primary and $28 \%$ of secondary infertility patients. Majority of the patients of primary infertility were in age group 21-25 years and that of secondary were between 2630 years. Majority of patients in both the groups had duration of 1-5 year of infertility. In our study tubal factors $(50 \%)$ contributed to majority of the infertility causes. Complication rate was minimum and was comparable to other standard studies.

Conclusions: Laparoscopic is the gold standard for diagnosing tubal and peritoneal disease, endometriosis and other pelvic pathology, because no other imaging technique gives the same degree of sensitivity or specificity. Hence diagnostic laparoscopy is an indispensable tool in the evaluation in the evaluation infertility.
\end{abstract}

Keywords: Diagnostic laparoscopy, Primary infertility, Secondary infertility, Tubal factors, Uterine factors

\section{INTRODUCTION}

Fertility in our culture stands for reproductively, growth and continuity. Reproduction is a basic expectation of life. To have a child is to continue the human life cycle.

It is the renewal of life. Society has placed a high premium on family and women have been encouraged to assume the biologic role of giving birth and nurturing children.
Infertility is a life crisis. The number of couples seeking medical help for infertility is increasing dramatically. ${ }^{1}$ The incidence of infertility in any community varies between $5-15 \% .^{2}$

Improved familiarity with and access to infertility services among the affluent and better-educated patients probably accounts for their greater use of these medical resources. ${ }^{3}$ 
According to Shaw's- Infertility implies apparent failure of a couple to conceive after one year of "unprotected" and regular intercourse. ${ }^{2}$

The most accepted definition of infertility "No pregnancy despite 12 months of regular intercourse" has probabilistic appeal. Given a monthly probability of pregnancy of $20 \%$, there is $93 \%$ chance of conception in 12 months. Therefore, the use of 1 year as a time interval for attempted conception before the diagnosis of infertility is applied, is both clinically and statistically justified.

According to Novak's, no evaluation of infertility can be considered complete unless laparoscopy is performed. ${ }^{3}$ Unexplained infertility is an ill-defined entity. It remains a clinical and scientific challenge.

Direct visualization of the pelvic organs can greatly improve the accuracy of diagnosis where clinical examination and ultrasound fail to identify the problems.

The benefits of the laparoscopic approach to surgery include - more precise surgery, superior hemostasis, less tissue handling and drying out, less pain and analgesic requirement, less scarring, improved cosmetic, quicker mobilization, shorter convalescence, reduced costs and quicker recovery.

Though for other lesions like fibroid and ovarian cysts, ultrasound may be helpful, peri adnexal adhesions and endometriosis can be diagnosed only by laparoscope. ${ }^{4}$

Ever since the advent of laparoscopy has been considered as one of the basic diagnostic procedure in the evaluation of an infertile woman. Laparoscopy plays a significant role not only in the diagnosis, but also in the treatment of female infertility. The investigation of the infertile couple cannot be considered as complete until a diagnostic laparoscopy has been performed.

The ability to visualize the peritoneal cavity and external aspects of pelvic structures aids in the diagnosis of pelvic-anatomic relationship, which can result from pelvic adhesions, leiomyomas, ovarian tumors, endometriosis (both peritoneal and deep), fallopian tube obstruction and other less common peritoneal pathologies. Leiomyomas, ovarian tumors can be detected radiologically, but precise anatomic relationships remain obscure. For these situations laparoscopy is clearly the diagnostic method. It evaluates tubal factors, ovarian factors, uterine factors in infertility.

The diagnosis of endometriosis by laparoscopy remains the gold standard. It allows complete survey of peritoneal surface as well as biopsy of suspicious lesions. Although USG and MRI imaging can detect endometriomas with high accuracy, they have only modest sensitivity in detecting peritoneal lesions. Laparoscopy on the other hand, is highly sensitive and specific.
Other unusual peritoneal pathologies detected by laparoscopy include pelvic tuberculosis, disseminated leiomyomatosis, endosalpingitis. It also helps in detecting uterine malformations, tubo-ovarian masses etc.

In tubercular infection of the tubes, the typical beaded appearance may be visualized. If tubes are blocked and there is concurrent Koch's endometritis, the uterus will show a typical bluish appearance on the surface. ${ }^{5}$

Templeton and Kerr reported their experience of laparoscopy and they feel that laparoscopy should replace the other methods of routine primary assessment of the genital tract. ${ }^{6}$ However, HSG, laparoscopy and hysteroscopy are complementary to each other.

The World Health Organization manual for standardized investigation of the infertile couple also recommends laparoscopy.

This study was conducted to assess the role of diagnostic laparoscopy in the investigation of female infertility and to evaluate the various causes of infertility like endometriosis, PCOD tubal and peritoneal factors, uterine anomalies, tuberculosis etc. by using diagnostic laparoscopy.

\section{METHODS}

All patients with infertility, anxious to conceive, attending the outpatient including referrals department from Jan 2015 to Jan 2017 of Sri Siddhartha Medical College, OBG Department were advised admission. After taking detailed history, they were subjected to clinical examination and investigations before taking them for diagnostic laparoscopy.

\section{Inclusion criteria}

All infertile patients (primary and secondary) anxious to conceive and willing to undergo diagnostic laparoscopy for evaluation of the same.

\section{Exclusion criteria}

Presence of azoospermia or severe oligospermia in the semen of the husband's of infertile patients.

- Routine investigations

- Special investigations like semen analysis - was done in all infertility patients to exclude male factor.

Diagnostic laparoscopy was performed in all the 60 cases. General anesthesia was employed. A thorough pelvic assessment was made.

Chromopertubation was done with methylene blue dye to assess the patency of tubes. Patients were discharged in the evening or next day morning. Any postoperative complications were noted. 


\section{RESULTS}

A cross-sectional clinical study consisting of 60 infertility patients, both primary and secondary is undertaken to know the role of diagnostic laparoscopy in the evaluation of infertility.

\section{Distribution of cases according to type of the infertility}

In the present study, 43 cases (72\%) were primary infertility and 17 cases (28\%) were of secondary infertility.

\section{Age distribution in cases of primary and secondary infertility}

In our study, majority of patients of primary infertility belonged to the age group of $21-25$ years $(51.1 \%)$ and that of secondary infertility to $26-30$ years $(46.6 \%)$. The minimum and maximum age of the patients with primary infertility was 20 and 40 years respectively. The minimum and maximum age of the patients with secondary infertility was 23 and 35 years respectively.

\section{Duration of infertility}

In our study, majority of patients of primary infertility $(62.7 \%)$ and that of secondary infertility $(58.8 \%)$ had duration of infertility of 1-5 years. Longest duration of infertility in primary was 16 years and that in secondary was 17 years.

\section{Obstetric history in secondary infertility}

In the present study, majority of the cases of secondary infertility - 10 cases $(69 \%)$ had previous history of abortion. Out of 10 cases, 5 had spontaneous and 5 had induced abortion. Out of 5 spontaneous, 3 had history of check curettage. Both of the 5 induced abortion cases gave history of instrumental evacuation.

\section{Uterine factors in infertility}

In present study, uterine factors accounted for $20.9 \%$ of infertility causes; Mullerian anomalies were found in 3 cases of primary infertility, out of which one had unicornuate uterus and another had sub septate uterus.

\section{Tubal factors in infertility}

In present study, tubal factors were responsible for $53.5 \%$ of primary and $30 \%$ of secondary infertility patients. Overall it accounted for $50 \%$ of cases. Out of 5 hydrosalpinx cases, 3 cases had bilateral and 4 had unilateral hydrosalpinx.

\section{Results of chromopertubation test}

The result of chromopertubation test, was done in all the 60 cases, is shown in Table 7. Delayed spillage was seen in 1 case of primary infertility. Chromopertubation test was not perceived in 1 primary infertility case due to dense adhesions.

\section{Ovarian factors in infertility}

Ovarian factors accounted for $28.3 \%$ of cases of infertility in our study. Of the 3 ovarian cysts, one was dermoid cyst, 1 was chocolate cyst of ovary and the other was simple ovarian cyst.

Table 1: Ovarian factors in infertility.

\begin{tabular}{|c|c|c|c|c|c|c|}
\hline \multirow{2}{*}{$\begin{array}{l}\text { Ovarian } \\
\text { factors }\end{array}$} & \multicolumn{2}{|c|}{$\begin{array}{l}\text { Primary } \\
(n=43)\end{array}$} & \multicolumn{2}{|c|}{$\begin{array}{l}\text { Secondary } \\
(\mathbf{n}=17)\end{array}$} & \multicolumn{2}{|c|}{$\begin{array}{l}\text { Total } \\
(n=60)\end{array}$} \\
\hline & No. & $\%$ & No. & $\%$ & No. & $\%$ \\
\hline PCOD & 6 & 14 & 2 & 11.7 & 8 & 13.3 \\
\hline Streak ovaries & 2 & 4.6 & - & - & 2 & 3.3 \\
\hline Ovarian cysts & 2 & 4.6 & 1 & 5.8 & 3 & 5 \\
\hline Bald ovaries & 3 & 6.9 & 1 & 5.8 & 4 & 6.6 \\
\hline Total & 13 & & 4 & & 17 & \\
\hline
\end{tabular}

\section{Peritoneal factors in infertility}

Peritoneal factors accounted for $20 \%$ of infertility cases. Pelvic endometriosis was found in a total of 3 cases. As mentioned before, endometriosis in the form of chocolate cyst of ovary was seen in 1 case. Total number of endometriosis cases in our study is $3(5 \%)$.

Isolated pelvic adhesions were seen in 5 cases and associated pelvic adhesions (with endometriosis and pelvic infection) were seen in another 3 cases. In addition, as already mentioned, peritubal adhesions were seen in a total of 12 cases.

\section{Causes of infertility at laparoscopy}

In many cases, there were more than one factor. The most important and significant one was considered. $11(18.3 \%)$ uterine factors, $30(50 \%)$ tubal factors, $17(28.3 \%)$ ovarian factors, $12(20 \%)$ peritoneal factors. However, inspite of thorough laparoscopic evaluation no cause was revealed in 7 cases $(11.6 \%)$ and were included under unexplained infertility.

\section{Complications of laparoscopic procedure}

In present study, no major complications were noted. Few patients had mild to moderate discomfort in abdomen. However severe abdominal pain noted in 2 cases and shoulder pain were noted in 1 case. Overall the complications rate was $5 \%$.

\section{DISCUSSION}

In the present study, incidence of primary infertility was $72 \%$ and that of secondary infertility was $28 \%$, which correlates with the studies conducted by Duignan et al 
$77 \%$ and $23 \%$, Templeton et al $74.9 \%$ and $25.1 \%$, Sharma et al $67.2 \%$ and $32.8 \%$ and Nakade KE et al $69.4 \%$ and $30.6 \%$ for primary and secondary infertility respectively. ${ }^{6-8}$ In the present study, majority of patients of primary infertility belonged to the age group of 21-25 years $(51.1 \%)$ and that of secondary infertility to the age group of 26-30 years $(46.6 \%)$. Present study correlates with that of Sharma et $\mathrm{al}^{8} 62.2 \%$ and $47.2 \%$ respectively.

\section{Obstetric history in secondary infertility}

In the present study, majority of patients $(69 \%)$ had a history of previous abortion is comparable to Sharma et $\mathrm{al}^{9} 51.3 \%$ of $\mathrm{H} / \mathrm{o}$ previous abortion.

Table 2: Obstetric history in secondary infertility.

\begin{tabular}{|lllll|}
\hline $\begin{array}{l}\text { Obstetric } \\
\text { category }\end{array}$ & $\begin{array}{l}\text { Bose } \\
\text { ST et al } \\
(\%)\end{array}$ & $\begin{array}{l}\text { Dor } \\
\text { et al } \\
(\%)\end{array}$ & $\begin{array}{l}\text { Sharma } \\
\text { R et al } \\
(\%)\end{array}$ & $\begin{array}{l}\text { Present } \\
\text { study } \\
(\%)\end{array}$ \\
\hline $\begin{array}{l}\text { Normal } \\
\text { delivery }\end{array}$ & 31.2 & 33.7 & 32.4 & 25 \\
\hline $\begin{array}{l}\text { Previous } \\
\text { abortion }\end{array}$ & 56.3 & 66.3 & 51.3 & 59 \\
\hline $\begin{array}{l}\text { Preterm } \\
\text { delivery }\end{array}$ & 12.5 & - & 8.1 & 5 \\
\hline $\begin{array}{l}\text { Intrauterine } \\
\text { death }\end{array}$ & - & - & 8.1 & 11 \\
\hline
\end{tabular}

\section{Uterine factors in infertility}

In the present study, uterine factors were responsible for infertility in $20.9 \%$ cases. In studies conducted by Chakraborti et al, uterine factors were responsible for $14.0 \%{ }^{9}$

Table 3: Tubal factors in infertility.

\begin{tabular}{|llll|}
\hline Factor & $\begin{array}{l}\text { Chakraborti } \\
\text { et al (\%) }\end{array}$ & $\begin{array}{l}\text { Bhide et } \\
\text { al }(\%)\end{array}$ & $\begin{array}{l}\text { Present } \\
\text { study }(\%)\end{array}$ \\
\hline $\begin{array}{l}\text { Bilateral } \\
\text { tubal block }\end{array}$ & 17.7 & 12.6 & 11.6 \\
\hline $\begin{array}{l}\text { Unilateral } \\
\text { tubal block }\end{array}$ & 5.0 & 10.2 & 6.6 \\
\hline $\begin{array}{l}\text { Peritubal } \\
\text { adhesions }\end{array}$ & - & - & 15 \\
\hline Hydrosalpinx & 9.2 & - & 8.3 \\
\hline $\begin{array}{l}\text { Tubo-ovarian } \\
\text { mass }\end{array}$ & 7.2 & 14.0 & 5 \\
\hline Total & 39.0 & 42.9 & $50 \%$ \\
\hline
\end{tabular}

Table shows various tubal factors contributing to infertility and also various studies conducted by Chakraborti et al, Bhide AG et al..$^{9,10}$

\section{Results of chromopertubation test}

Sharma $\mathrm{R}$ et al study shows the results of chromopertubation as negative in $17.7 \%$ bilateral positive in $55.5 \%$, unilateral positive in $3.5 \%$, delayed spillage in $6.2 \%$ and nor perceived in $16.8 \% .^{11}$ In the present study the results are $15 \%, 66.6 \%, 13.3 \%, 1.6 \%$ and $3.3 \%$ respectively.

\section{Ovarian factors in infertility}

Ovarian factors in present study was PCOS $13.3 \%$, ovarian cyst $5 \%$, streak ovaries $3.3 \%$ and total of ovarian factors contributed $28.3 \%$. In Bhide AG et al study it was $3.9 \%, \quad 5.3 \%, \quad 0.8 \%$ and $9.7 \%$ respectively and Chakraborthy et al study it was $11.4 \%, 8.0 \%$ respectively. ${ }^{9,10}$

\section{Peritoneal factors}

In the present study the peritoneal factors contributing are endometriosis $5 \%$, pelvic tuberculosis $1.6 \%$, pelvic adhesions $8.3 \%$ and total of $20 \%$ while Bhide et al had $10.9 \%$ of total cases, Sharma et al had $6.6 \%$ and $10.6 \%$ and Chakraborthy et al had $4.6 \%$ and $8.3 \%$ in endometriosis and pelvic tuberculosis respectively. ${ }^{8-10}$

\section{Complications of laparoscopy}

RCOG survey report reports complications of laparoscopy of laparoscopy of 36/1000 cases whereas in the present study it is $50 / 1000$ cases. $^{12}$

Funding: No funding sources

Conflict of interest: None declared

Ethical approval: The study was approved by the Institutional Ethics Committee

\section{REFERENCES}

1. Aral SO, Cates W Jr. The increasing concern with infertility, Why now? Science. 1983;250:2327.

2. VG Padubidri, SN Daftary, Shaw's text book of Gynaecology, $13^{\text {th }}$ Ed. Reed Elsevier India Pvt Ltd; 198.

3. Berek JS, Rinehart RD, Hillard PA, Adashi EY. Novak's Gynaecology. 13 ${ }^{\text {th }}$ Ed. Lippincott Williams \& Wilkins;973-974, 979, 983.

4. Gomel V, Taylor PJ. Diagnostic laparoscopy in infertility. Chapter 9, In diagnostic and operative gynaecologic laparoscopy. Mosby Year book Medical Publishers; 1995.

5. Patel DN, Dalai DS. Laparoscopic equipment. Gynaecologic Endoscopy. 1986;3-20:57-61.

6. Templeton AA, Kerr MG. An assessment of laparoscopy as the primary investigation in the sub fertile female. Br J Obst Gynaecol. 1977;84:3564-5.

7. Duignan NM. One thousand consecutive cases of diagnostic Laparoscopy. J Obst Gynecol $\mathrm{Br} \mathrm{C}$ Wealth. 1972;79:1016-24.

8. Sharma R, Sharma V. The infertile woman; a study of 120 cases. J Indian Med Asssoc, 1991;89(2):3132. 
9. Chakraborti DK, Kole SK. Diagnostic laparoscopy in gynaecologic disorders. J Obstet Gynecol. 1990;40:262-5.

10. AG Bhide. Laparoscopic evaluation of the etiopathology of infertility. J Obstet Gynecol India. 1990;40:680-2.

11. Sharma R, Taly A, Guleri AS. Laparoscopic evaluation of cases of primary and secondary infertility. J Obstet Gynecol India. 1997;47(4):36671.
12. Chamberlain G, Brown JC. Fertility Committee of RCOG gynaecological laparoscopy. The report of the world party of the confidential enquiry into gynaecological laparoscopy. 1992:126.

Cite this article as: Hema KR, Lalitha HS. Evaluation of role of laparoscopy in determining etiology of infertility. Int J Reprod Contracept Obstet Gynecol 2017;6:5322-6. 